\title{
Segmented block copolymers based on dimerized fatty acids and poly(butylene terephthalate)
}

\author{
H. J. Manuel and R. J. Gaymans* \\ Department of Chemical Technology, University of Twente, PO Box 217, \\ 7500 AE Enschede, The Netherlands \\ (Received 9 March 1992; revised 16 June 1992)
}

\begin{abstract}
Segmented block copolymers based on dimerized fatty acids and poly(butylene terephthalate) (PBT) have been synthesized in the melt. Branched $\mathrm{C}_{36}, \mathrm{C}_{44}$ and $\mathrm{C}_{70}$ dimerized fatty acids with a low degree of unsaturation were used. The fraction of PBT was varied from 50 to $100 \mathrm{wt} \%$. The resulting polymers were analysed with d.s.c. and d.m.a. The glass transition temperature $\left(T_{\mathrm{g}}\right)$ increased with increasing weight fraction of PBT. $T_{\mathrm{g}}$ decreased with increasing molecular mass of the dimerized fatty acid. The melting temperature increased with increasing weight fraction of PBT and increasing molecular mass of the dimerized fatty acid. The range of service temperatures of the thermoplastic elastomers can therefore be enlarged by using dimerized fatty acid with a high molecular mass. With increasing molecular mass of the dimerized fatty acid the storage modulus and the melting and crystallization enthalpy did not change significantly. The storage modulus can be described as a function of the volume fraction of crystalline PBT, but is not a function of the type of dimerized fatty acid.
\end{abstract}

(Keywords: dimer acid; dimerized fatty acid; segmented block copolymer; poly(butylene terephthalate); poly(ester ester); thermoplastic elastomer)

\section{INTRODUCTION}

Segmented block copolymers are polymers that consist of different types of segments that alternate along the polymer backbone. Each segment of the polymer backbone has its own properties and transition temperatures. When proper monomers are chosen segmented block copolymers can be synthesized with elastomeric properties. One segment (A) must possess a low elasticity modulus and a low glass transition temperature $\left(T_{\mathrm{g}}\right)$. This segment imparts elastomeric properties to the material and, therefore, is often called the soft phase. The other segment (B) is designed to undergo some sort of association with other B segments so that it can form physical crosslinks. This segment will then impart dimensional stability to the material and, therefore, is often called the hard phase. Since the crosslinks of the material are of a physical nature, the materials with elastomeric properties can be processed in the melt by thermoplastic moulding techniques. For this reason, the materials are called thermoplastic elastomers (TPEs).

An example of a commercial TPE that has been studied extensively in the literature ${ }^{1}$ is the segmented block copoly(ether ester). Commercial block copoly(ether ester)s are usually based on poly(tetramethylene oxide) (PTMO) and poly(butylene terephthalate) (PBT) as the rubbery and semicrystalline components, respectively. These materials and their modifications are known under many tradenames such as Hytrel (DuPont), Arnitel (AKZO) and Pelprene (Toyobo). These materials couple

* To whom correspondence should be addressed

0032-3861/93/030636-06

(C) 1993 Butterworth-Heinemann Ltd.

636 POLYMER, 1993, Volume 34, Number 3 interesting properties such as high melting temperature $\left(T_{\mathrm{m}}\right)$, low $T_{\mathrm{g}}$, high tensile and tear strengths with ease of processing.

One of the disadvantages of PTMO in TPEs is that it is prone to oxidative degradation ${ }^{2-5}$ and hydrolysis ${ }^{5}$ at elevated temperatures. It also degrades at ambient temperatures in sunlight ${ }^{6,7}$. For these reasons commercial copoly(ether ester)s are stabilized with various stabilizers $^{2-5,7-10}$.

An alternative to polyethers in TPEs are saturated fatty acids. Hoeschele ${ }^{11}$ synthesized segmented block copolymers with a $\mathrm{C}_{36}$ dimerized fatty acid as the soft phase. All the properties concerning degradation stability were improved while most other properties were not influenced significantly. The properties at lower temperatures, however, showed poorer results due to the higher $T_{\mathrm{g}}$ value. This is probably caused by the low molecular mass of the dimerized fatty acid.

Commercial dimerized fatty acids are usually synthesized by dimerization of unsaturated $\mathrm{C}_{18}$ fatty acids such as oleic, linoleic and linolenic acids. This yields mixtures of branched $\mathrm{C}_{36}$ dimerized fatty acids with a molecular mass of $\sim 565 \mathrm{~g} \mathrm{~mol}^{-1}$. Unichema Chemie BV (Gouda, The Netherlands) synthesized $\mathrm{C}_{44}$ dimerized fatty acid by employing $C_{22}$ fatty acids ${ }^{12}$. Also, a $C_{70}$ dimerized fatty acid was synthesized by coupling two $\mathrm{C}_{36}$ dimerized fatty acids $^{13}$. These new types of dimerized fatty acid have a high purity and a low unsaturation level.

The aim of this work is to study the synthesis and properties of segmented block copolymers with PBT as the hard phase and dimerized fatty acids with different molecular masses as the soft phase. 


\section{EXPERIMENTAL}

\section{Materials}

Dimethylterephthalate (DMT), 1,4-butanediol (BDO) and tetrabutyl o-titanate (all synthetic grade) were purchased from Merck, Hohenbrunn, Germany. The dimerized fatty acids were obtained from Unichema Chemie, Gouda, The Netherlands.

Some properties of the dimerized fatty acids are given in Table 1. The iodine value is the number of unsaturated bonds present; the values indicate that a low number is present.

The purity of the dimerized fatty acids is also given in Table 1. Pure dimerized fatty acid would consist of $100 \%$ dimer. Some monomer remains in the material. Also, a portion of trifunctional trimer is formed as a by-product in the reaction. The intermediate fraction consists partly of monofunctional fatty acid ( $>\mathrm{C}_{18}$ fatty acid) and partly of bifunctional dimerized fatty acid $\left(<\mathrm{C}_{36}\right.$ dimerized fatty acid).

\section{Synthesis of segmented block copolymers ${ }^{11}$}

Batches of copolymer $(50 \mathrm{~g})$ were synthesized by placing BDO, DMT and dimerized fatty acid in an agitated round-bottom flask, fitted for distillation. A stainless steel stirrer with a paddle, cut to conform with the internal radius of the flask, was positioned a few millimetres above the bottom of the flask. Agitation was started while nitrogen was led into the flask. The flask was placed in an oil bath at $160^{\circ} \mathrm{C}$, agitated for $5 \mathrm{~min}$ and then $0.1 \mathrm{wt} \%$ tetrabutyl o-titanate was added. Methanol distilled from the reaction mixture as the temperature was slowly raised to $240^{\circ} \mathrm{C}$ over a period of $1 \mathrm{~h}$. At $240^{\circ} \mathrm{C}$ the pressure was reduced in $15 \mathrm{~min}$ to $\sim 0.5-1 \mathrm{~mm} \mathrm{Hg}$ to distil excess BDO from the reaction mixture. The reaction mixture was agitated for another hour and allowed to cool down slowly under vacuum to room temperature. A white polymeric product was produced.

\section{Synthesis of amorphous polymers (dimerized fatty acid with $B D O$ )}

To determine the $T_{\mathrm{g}}$ of the pure amorphous phase two polyesters of $\mathrm{C}_{36}$ and $\mathrm{C}_{44}$ dimerized fatty acids with BDO were synthesized (no DMT). The same procedure was followed as described for the TPEs except that no vacuum was employed. The products were transparent viscous liquids.

\section{Characterization}

Viscometry. The logarithmic viscosity number (inherent viscosity) of $1 \mathrm{gl}^{-1}$ solutions of copolymer in $m$-cresol (Merck, analytical grade) was determined with an Ubbelohde viscometer at $25^{\circ} \mathrm{C}$.

End group titration. The purely amorphous polyesters from dimerized fatty acid with BDO were titrated to determine the concentration of carboxyl end groups. The concentration was measured by dissolving $200 \mathrm{mg}$ of product in freshly distilled benzyl alcohol followed by titration with potassium hydroxide in tertiary butanol. Titration was carried out with a glass calomel electrode under nitrogen, to minimize oxidation of benzyl alcohol, in a titroprocessor (Metron 636). All chemicals were analytical grade and obtained from Merck. The numberaverage molecular masses of the amorphous polyesters, as determined by end group titration, were $2100 \pm 110$ and $2470 \pm 90 \mathrm{~g} \mathrm{~mol}^{-1}$ for the $C_{36}$ and $C_{44}$ polyesters, respectively.

$W A X S$ measurements were performed on stretched samples of 1,6-hexane diamine-dimerized fatty acid polymers. Ni-filtered $\mathrm{CuK} \alpha$ radiation was generated by a Phillips PW 1700 diffractometer. A scan was performed from 1.01 to $60^{\circ}$, at a speed of $25 \mathrm{~s}$ per degree.

D.s.c. Thermal properties were measured with a Perkin-Elmer DSC-7. Samples (4-8 mg) of the asprepared copolymers were dried in vacuo at $100^{\circ} \mathrm{C}$ for $24 \mathrm{~h}$ prior to testing. D.s.c. curves were obtained using the following procedure (heating/cooling rate, $20^{\circ} \mathrm{C} \mathrm{min}^{-1}$ ): first heating run from 50 to $40^{\circ} \mathrm{C}$ above the $T_{\mathrm{m}}$; equilibration for $8 \mathrm{~min}$; cooling run to $50^{\circ} \mathrm{C}$; second heating run to $40^{\circ} \mathrm{C}$ above the $T_{\mathrm{m}}$.

The crystallization temperature $\left(T_{\mathrm{c}}\right)$ and $T_{\mathrm{m}}$ were taken as the maxima in the cooling and second heating runs respectively. The crystallization enthalpy $\left(\Delta H_{\mathrm{c}}\right)$ and melting enthalpy $\left(\Delta H_{\mathrm{m}}\right)$ were also taken from these runs. The absolute error in $T_{c}$ and $T_{m}$ was $\pm 2^{\circ} \mathrm{C}$. The absolute errors in $\Delta H_{\mathrm{m}}$ and $\Delta H_{\mathrm{c}}$ were $\pm \overline{4}$ and $\pm 2 \mathrm{~J} \mathrm{~g}^{-1}$, respectively.

D.m.a. Torsion bars (approximate dimensions $80 \times 9$ $\times 2 \mathrm{~mm}$ ) were prepared by compression moulding of the as-prepared copolymers. The copolymers were placed between the heating plates of a hydraulic press (Lauffer), compressed and kept at a temperature $\sim 40^{\circ} \mathrm{C}$ above the $T_{\mathrm{m}}$ for $7 \mathrm{~min}$, then the cooling of the heating plates was started. The bars were subsequently dried for $18 \mathrm{~h}$ in vacuo at $100^{\circ} \mathrm{C}$. The test bars were heated from $-100^{\circ} \mathrm{C}$ to the onset of melting at a heating rate of $\sim 1^{\circ} \mathrm{C} \mathrm{min}^{-1}$ at a resonance frequency of $1 \mathrm{~Hz}$. Torsion moduli were calculated with a computer-controlled Myrenne torsion pendulum. The maximum of the loss modulus was taken as the $T_{\mathrm{g}}$. The absolute error in $T_{\mathrm{g}}$ was $\pm 2{ }^{\circ} \mathrm{C}$. The relative error in the moduli was $\pm 5 \%$.

The $T_{\mathrm{g}}$ of the pure amorphous polyesters (dimerized fatty acid-BDO) was determined by an indirect route. First, a piece of cloth with the right dimensions was cut. The piece of cloth was then impregnated with the polyester and dried at $40^{\circ} \mathrm{C}$ for $5 \mathrm{~h}$. The specimen was measured under the same conditions as described above.

\section{RESULTS AND DISCUSSION}

\section{Dimerized fatty acids}

$W A X S$. The average number of carbon atoms directly between the carboxyl groups of the $\mathrm{C}_{36}$ dimerized fatty acid was determined with WAXS. The number of carbon atoms could not be determined for $\mathrm{C}_{44}$ and $\mathrm{C}_{70}$ dimerized fatty acid. The result is given in Table 1. For the $\mathrm{C}_{36}$ dimerized fatty acid 13 carbon atoms can be found directly between the carboxyl groups. The branched side groups therefore contain 21 carbon atoms.

\section{Segmented block copolymers}

Viscometry. The logarithmic viscosity numbers of all the synthesized block copolymers are given in Table 2. They compare well with the results of Hoeschele ${ }^{2}$ on copolymers based on $\mathrm{C}_{36}$ dimerized fatty acid and PBT. In all cases, polymers were formed with a high enough molecular mass to allow torsion bars to be compression 
Table 1 Properties of dimerized fatty acids

\begin{tabular}{|c|c|c|c|c|c|c|c|c|c|}
\hline \multicolumn{2}{|c|}{ Dimerized fatty acid } & \multirow[b]{2}{*}{$\begin{array}{l}{[-\mathrm{COOH}]} \\
\left(\mathrm{meqg}^{-1}\right)\end{array}$} & \multirow[b]{2}{*}{$\begin{array}{l}\text { Iodine value } \\
(\mathrm{mg} \mathrm{I} \text { per } 100 \mathrm{~g})\end{array}$} & \multicolumn{4}{|c|}{ Composition } & \multirow{2}{*}{$\begin{array}{l}\text { WAXS } \\
\text { Repeating } \\
\text { unit }^{a} \\
(\AA)\end{array}$} & \multirow[b]{2}{*}{$\mathbf{C}^{b}$} \\
\hline $\begin{array}{l}\text { Tradename/ } \\
\text { laboratory } \\
\text { code }\end{array}$ & $\begin{array}{l}\text { Number of } \\
\text { carbon } \\
\text { atoms }\end{array}$ & & & $\begin{array}{l}\text { Monomer } \\
(w t \%)\end{array}$ & $\begin{array}{l}\text { Intermediate } \\
(w t \%)\end{array}$ & $\begin{array}{l}\text { Dimer } \\
(w t \%)\end{array}$ & $\begin{array}{l}\text { Trimer } \\
(w t \%)\end{array}$ & & \\
\hline Pripol 1008 & 36 & 3.46 & 3.8 & 0.1 & 0.5 & 99.0 & 0.5 & 25 & 13 \\
\hline UCN 83.033 & 44 & 2.97 & $<7$ & 0.1 & $5.0^{d}$ & 93.5 & 1.5 & - & - \\
\hline$-^{c}$ & 70 & - & $<7$ & 4.0 & - & 96.0 & - & - & - \\
\hline
\end{tabular}

${ }^{a}$ Repeating unit of amide of dimerized fatty acid with 1,6-hexanediamine

${ }^{b}$ Number of carbon atoms directly between $\mathrm{COOH}$ groups

'Dimethylester of $\mathrm{C}_{70}$ dimerized fatty acid

${ }^{d}$ Mainly other dimerized fatty acids

Table 2 Logarithmic viscosity numbers, d.s.c. data and torsional data of copolymers based on dimerized fatty acids and varying PBT fractions

\begin{tabular}{|c|c|c|c|c|c|c|c|c|c|c|c|}
\hline $\begin{array}{l}\text { Material } \\
\text { acid }\end{array}$ & $W_{\mathrm{PBT}}^{a}$ & $\begin{array}{l}\eta_{\text {inh }} \\
\left(\mathrm{dl} \mathrm{g}^{-1}\right)\end{array}$ & $n^{b}$ & $\begin{array}{l}T_{\mathrm{m}} \\
\left({ }^{\circ} \mathrm{C}\right)\end{array}$ & $\begin{array}{l}T_{\mathrm{c}} \\
\left({ }^{\circ} \mathrm{C}\right)\end{array}$ & $\begin{array}{l}\Delta H_{\mathrm{m}} \\
\left(\mathrm{Jg}^{-1}\right)\end{array}$ & $\frac{-\Delta H_{\mathrm{c}}}{\left(\mathbf{J} \mathbf{g}^{-1}\right)}$ & $\begin{array}{l}\alpha_{10 t}{ }^{c} \\
(\%)\end{array}$ & $\begin{array}{l}\alpha_{\mathrm{PBT}}{ }^{c} \\
(\%)\end{array}$ & $\begin{array}{c}T_{\mathrm{g}} \\
\left({ }^{\circ} \mathrm{C}\right)\end{array}$ & $\begin{array}{l}G^{\prime}\left(30^{\circ} \mathrm{C}\right) \\
(\mathrm{MPa})\end{array}$ \\
\hline $\mathrm{PBT}^{d}$ & 1.00 & 1.66 & - & 223 & 190 & 55 & - & 40 & 40 & 50 & 2600 \\
\hline$C_{36}$ & 0.78 & 1.22 & 10.0 & 208 & 156 & 31 & 38 & 26 & 34 & -3 & 153 \\
\hline $\mathrm{C}_{36}$ & 0.70 & 0.96 & 6.6 & 203 & 153 & 29 & 36 & 25 & 36 & -15 & 90 \\
\hline $\mathrm{C}_{36}$ & 0.60 & 0.90 & 4.2 & 185 & 146 & 21 & 32 & 22 & 37 & -26 & 58 \\
\hline$C_{36}$ & 0.50 & 0.46 & 2.8 & 171 & 116 & 16 & 22 & 15 & 30 & -32 & 28 \\
\hline $\mathrm{C}_{44}$ & 0.80 & 0.37 & 13.3 & 212 & 168 & 42 & 45 & 31 & 39 & -12 & 168 \\
\hline $\mathrm{C}_{44}$ & 0.60 & 0.44 & 5.0 & 194 & 143 & 26 & 32 & 22 & 37 & -36 & 62 \\
\hline$C_{44}$ & 0.50 & 0.26 & 3.3 & 181 & 152 & 14 & 23 & 16 & 32 & -40 & 42 \\
\hline $\mathrm{C}_{70}$ & 0.81 & 0.25 & 21.3 & 217 & 178 & 45 & 45 & 31 & 38 & -34 & 230 \\
\hline $\mathrm{C}_{70}$ & 0.61 & 0.47 & 7.8 & 211 & 146 & 27 & 32 & 22 & 37 & -37 & 60 \\
\hline $\mathrm{C}_{70}$ & 0.51 & 0.50 & 5.2 & 199 & 142 & 18 & 24 & 17 & 33 & -41 & 36 \\
\hline
\end{tabular}

a Weight fraction of PBT

${ }^{b} n=x /(1-x)$, where $x=$ molar fraction of PBT repeating units

$c \alpha_{\text {tot }}=\Delta H_{\mathrm{c}} / 144.5 ; \alpha_{\mathrm{PBT}}=\alpha_{\mathrm{tot}} / W_{\mathrm{PBT}}$

${ }^{d}$ From reference 25

moulded. As already predicted by Hoeschele, a few exploratory tests showed that the logarithmic viscosity number could be increased by post condensation. The as-prepared copolymers were used without post condensation for further tests.

D.s.c. D.s.c. data of the dried copolymers are given in Table 2. The $T_{\mathrm{m}} \mathrm{s}$ of the copolymers are lower than that of pure PBT. The $T_{\mathrm{m}}$ is usually a function of the PBT block length ${ }^{14,15}$. In Figure 1 the $T_{\mathrm{m}}$ of the copolymers based on dimerized fatty acids is plotted versus the number-average hard segment sequence length $(n)$. Data on copoly(ether ester)s based on PTMO (PTMO glycol $1000 \mathrm{~g} \mathrm{~mol}^{-1}$ ) and PBT from reference 14 are also included. The average hard segment sequence length is calculated from the known molar fraction of PBT repeating units $(x)$, according to $n=x /(1-x)$. The $T_{\mathrm{m}}$ is solely a function of the block length. This can be explained as being due to the change in thickness of the PBT lamellae. In the melting point depression of random copolymers the concentration and interaction parameter of the amorphous phase also play a role $^{16}$. In our segmented block copolymers no effect of interaction parameters on $T_{\mathrm{m}}$ is observed (the nature of the amorphous phase does not influence $T_{\mathrm{m}}$ significantly; all data fit the line well). The block length is a function of

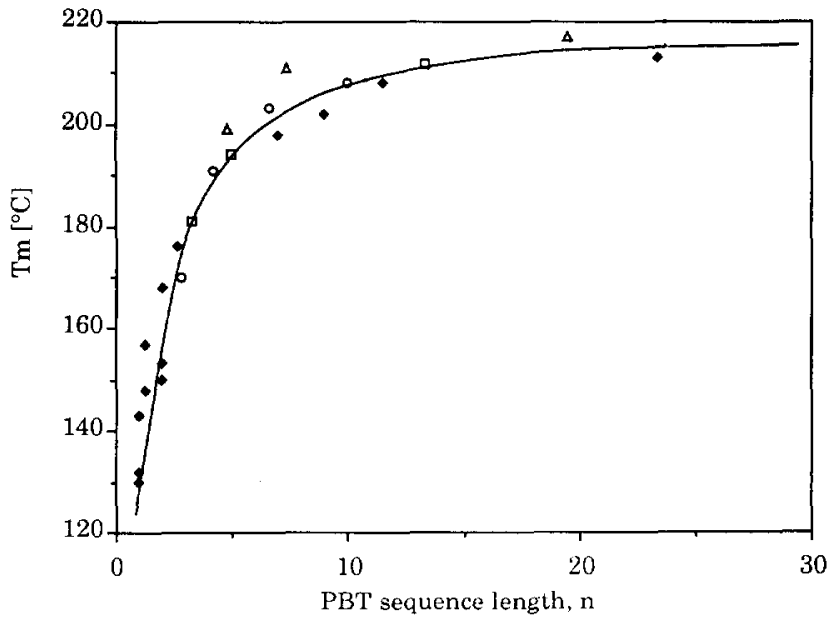

Figure 1 Melting temperature as a function of the sequence length of PBT segments. Copolymers based on PBT and: (O) $\mathrm{C}_{36}$ dimerized fatty acid; (口) $\mathrm{C}_{44} ;(\triangle) \mathrm{C}_{70} ;(\Delta)$ PTMO-glycol $1000 \mathrm{~g} \mathrm{~mol}^{-1}$ (data from ref. 14)

the molecular mass of the amorphous phase and the weight fraction of PBT. The $T_{\mathrm{m}}$ can therefore be increased at a constant composition by increasing the molecular mass of the soft block. 
The $T_{\mathrm{c}}$ behaves much the same as $T_{\mathrm{m}}$ with different dimerized fatty acids and composition. Its value is usually some $40-60^{\circ} \mathrm{C}$ lower. This difference is larger than for pure $\mathrm{PBT}$ reflecting the increased difficulty to crystallize.

The $\Delta H_{\mathrm{m}}$ and $\Delta H_{\mathrm{c}}$ increase with increasing weight fraction of PBT. Strangely, $\Delta H_{\mathrm{m}}$ and $\Delta H_{\mathrm{c}}$ do not change significantly with the molecular mass of the dimerized fatty acids at a constant weight fraction of PBT. The enthalpy is influenced by composition only.

The calculated total weight fraction of crystalline material in the TPEs $\left(\alpha_{\text {tot }}\right)$ and the weight fraction of crystallized PBT segments $\left(\alpha_{\mathrm{PBT}}\right)$ are also given in Table 2. They increase to the values for pure PBT at higher weight fractions of PBT: $\alpha_{\text {tot }}$ increases because the total amount of crystallizable material increases; $\alpha_{\mathrm{PBT}}$ increases because the concentration of short PBT segments that do not crystallize decreases.

D.m.a. Figures 2-4 show storage and loss moduli of the dried copolymers based on PBT and dimerized fatty acids with different molecular masses. In Table $2, T_{\mathrm{g}}$ and storage moduli above $T_{\mathrm{g}}$ are presented. The curves of the storage moduli show rubber plateaux that stay constant over long temperature ranges and decrease over a short range near the $T_{\mathrm{m}}$. The loss moduli show a single sharp maximum $\left(T_{\mathrm{g}}\right)$ at lower PBT concentrations. At higher concentrations the maxima shift to higher temperatures and broaden considerably. The broadening is especially
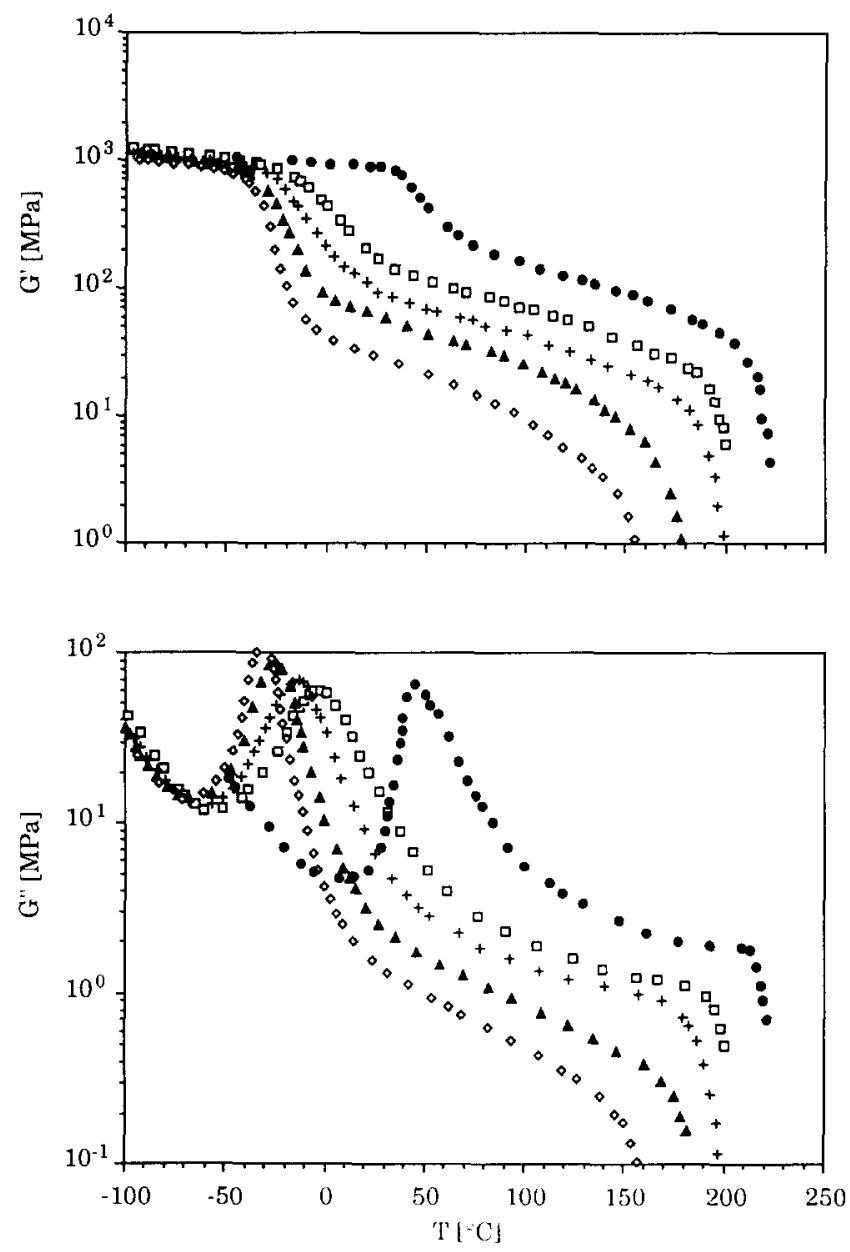

Figure 2 Torsional storage and loss moduli of copolymers based on $\mathrm{C}_{36}$ dimerized fatty acid and varying amounts of $\mathrm{PBT}\left(W_{\mathrm{PBT}}\right):(O) 1.00$; (ㅁ) $0.78 ;(+) 0.70 ;(\Delta) 0.60 ;(\diamond) 0.50$
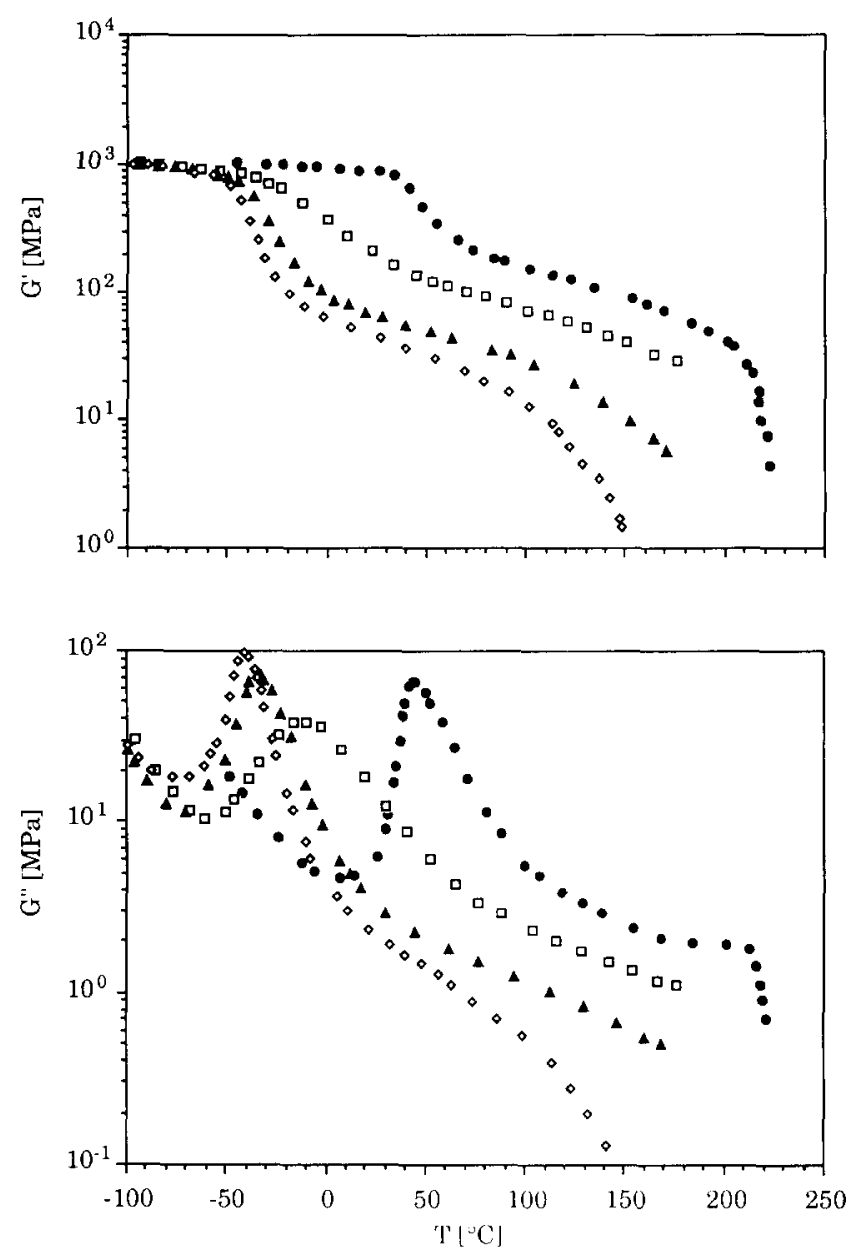

Figure 3 Torsional storage and loss moduli of copolymers based on $\mathrm{C}_{44}$ dimerized fatty acid and varying amounts of PBT $\left(W_{\mathrm{PBT}}\right)(\mathrm{O}) 1.00$;

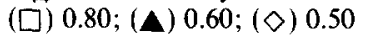

distinct when dimerized fatty acids with a higher molecular mass are used.

Lilaonitkul et al. ${ }^{17}$ found a shift in the $\tan \delta$ for PBT-PTMO-glycol $1000 \mathrm{~g} \mathrm{~mol}^{-1}$ polymers towards higher temperatures at higher concentrations of PBT. Also the peaks broadened significantly. They concluded that this was due to the formation of more than one amorphous phase in polymers with high PBT concentrations. The same can probably be concluded for TPEs based on dimerized fatty acids.

In Figure 5, $T_{\mathrm{g}}$ is plotted versus the weight fraction of PBT. For comparison, data on copoly(ether ester)s based on PTMO-glycol $650 / 1000 \mathrm{~g} \mathrm{~mol}^{-1}$ and PBT are also given. The copoly(ether ester)s were synthesized in our laboratory under the same reaction conditions as applied to the materials based on the dimerized fatty acids. The PTMO-glycol was purchased from BASF, Ludwigshafen, Germany. Data on the pure amorphous polyester $\left(C_{36}\right.$ or $\mathrm{C}_{44}$ dimerized fatty acid with $\mathrm{BDO}$ ) are also given.

From the figure it can be seen that the $T_{g}$ s of the purely amorphous phases at low weight fraction of PBT are close to each other. The $T_{\mathrm{g}} \mathrm{s}$ of the purely amorphous polyesters of $\mathrm{C}_{36}$ and $\mathrm{C}_{44}$ dimerized fatty acids with $\mathrm{BDO}$ are -55 and $-55^{\circ} \mathrm{C}$, respectively. For PTMO-glycol $650 \mathrm{~g} \mathrm{~mol}^{-1}$ and PTMO-glycol $1000 \mathrm{~g} \mathrm{~mol}^{-1}$ the $T_{\mathrm{g}}$ is $-65^{\circ} \mathrm{C}$. The differences that occur at higher weight fractions of PBT must therefore be caused by differences in the molecular mass of the amorphous phases and 

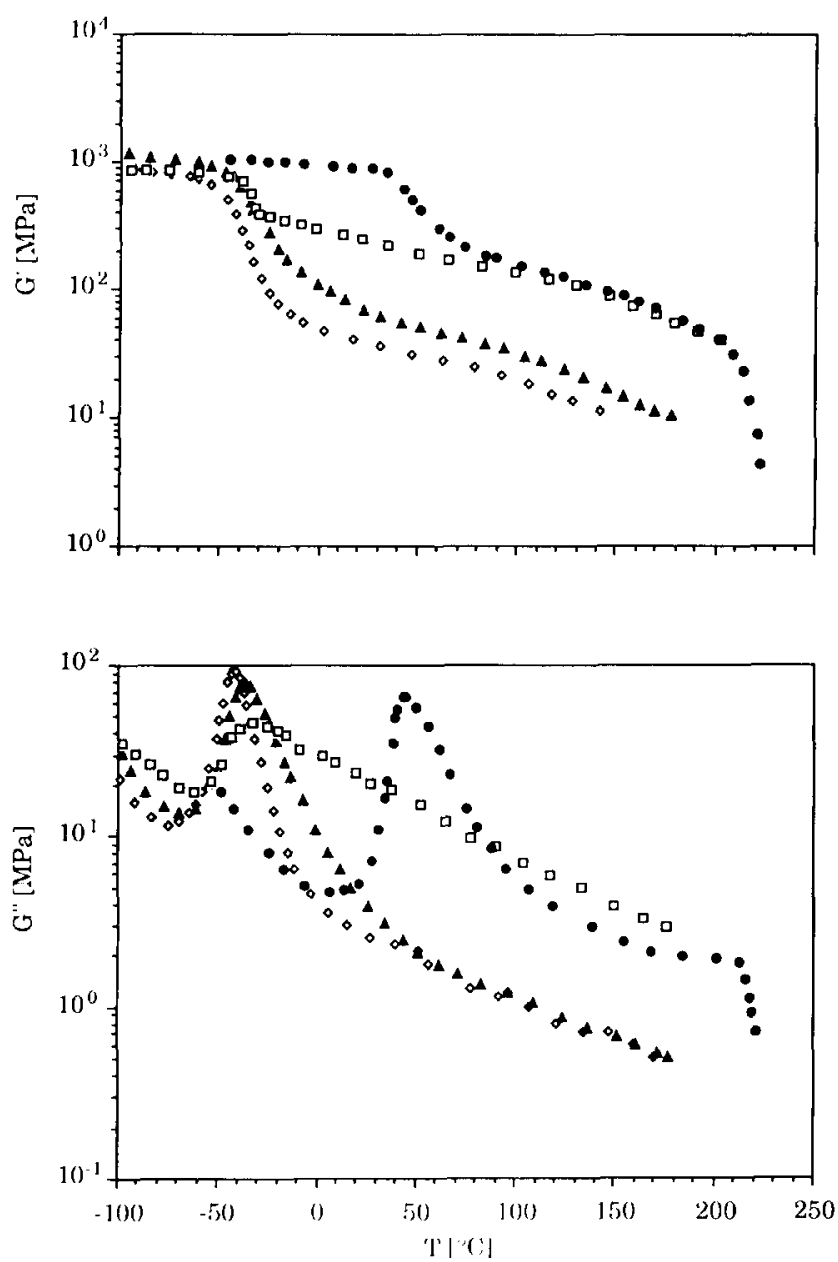

Figure 4 Torsional storage and loss moduli of copolymers based on $\mathrm{C}_{70}$ dimerized fatty acid and varying amounts of PBT $\left(\boldsymbol{W}_{\mathrm{PBT}}\right):(\boldsymbol{\theta})$ $1.00 ;(\square) 0.81 ;(\Delta) 0.61 ;(\diamond) 0.51$

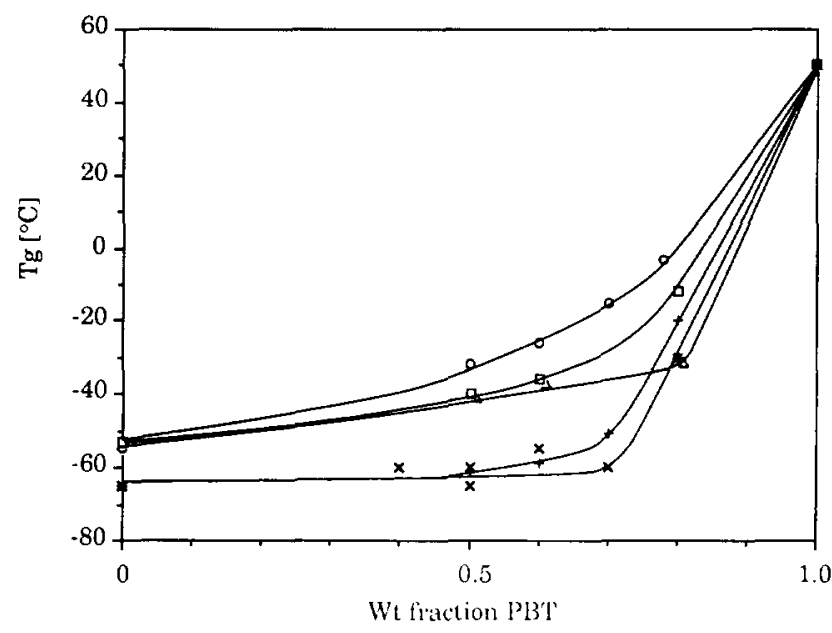

Figure 5 Glass transition temperature as a function of the weight fraction of PBT. Copolymers based on PBT and: $(O) \mathrm{C}_{36}$ dimerized fatty acid; ( $\square) \mathrm{C}_{44} ;(\triangle) \mathrm{C}_{70} ;(+)$ PTMO-glycol $650 \mathrm{~g} \mathrm{~mol}^{-1} ;(x)$ PTMO-glycol $1000 \mathrm{~g} \mathrm{~mol}^{-1}(+$ and $\times$, this work)

differences in the compatibility between the amorphous phase and PBT.

As can be seen from the figure, the $T_{\mathrm{g}}$ of the TPEs based on the $\mathrm{C}_{36}$ dimerized fatty acid is at a higher level than that of the PTMO materials. If these poor properties are in part due to the short length of the amorphous phase they can be improved by using dimerized fatty acids with higher molecular masses. Indeed, this can be concluded from the figure. In particular, the TPE based on $\mathrm{C}_{70}$ dimerized fatty acid shows a curve that stays at a low level at high weight fractions of PBT.

A final comment involves the curves of the PTMO materials. The figure shows a constant value for $T_{\mathrm{g}}$ with increasing weight fraction of PBT until, at a certain point, the $T_{\mathrm{g}}$ value climbs with a steep slope to the $T_{\mathrm{g}}$ of pure PBT. Cella ${ }^{14}$ published a similar figure of $T_{\mathrm{g}}$ versus weight fraction of PBT for TPEs based on PTMO $\left(1000 \mathrm{~g} \mathrm{~mol}^{-1}\right)$. He measured the $T_{\mathrm{g}}$ by d.s.c. This figure shows a much more gradual increase in $T_{g}$ versus weight fraction of PBT. If the amorphous phase is indeed composed of one homogeneous mixture of amorphous PBT and PTMO this result is to be expected. Our results for the PTMO materials and the $\mathrm{C}_{70}$ copolymer show a different behaviour. Possibly due to heterogeneity the $T_{\mathrm{g}}$ might primarily be dictated by a portion of the amorphous phase that consists mainly of polyether (or dimerized fatty acid). Another portion, that consists mainly of PBT, might cause a broadening of the peak, especially at high weight fractions of PBT. The portion rich in polyether (or dimerized fatty acid) decreases rapidly at high weight fractions of PBT, which will cause the steep increase in $T_{\mathrm{g}}$. As a result, peak broadening will then diminish at very high weight fractions of PBT. This can indeed be seen in Figures 2-4.

Other authors have also found evidence for a system with more than two phases. Perego et al. ${ }^{18}$, for example, concluded that heterogeneity existed in copoly(ether ester)s according to deviations in electron density measurements by SAXS and WAXS.

In Figure 6 the storage moduli of the copolymers based on dimerized fatty acids and PBT are plotted as a function of the volume fraction of crystalline PBT. The volume fraction of crystalline material can be calculated from the melting/crystallization enthalpy ${ }^{19}$.

The storage moduli increase with increasing volume fraction of crystalline PBT. From Table 2 it can be concluded that this volume fraction is influenced by the PBT content but seems to be independent of the type of dimerized fatty acid used. The phenomenon that the composition is the only factor that influences properties

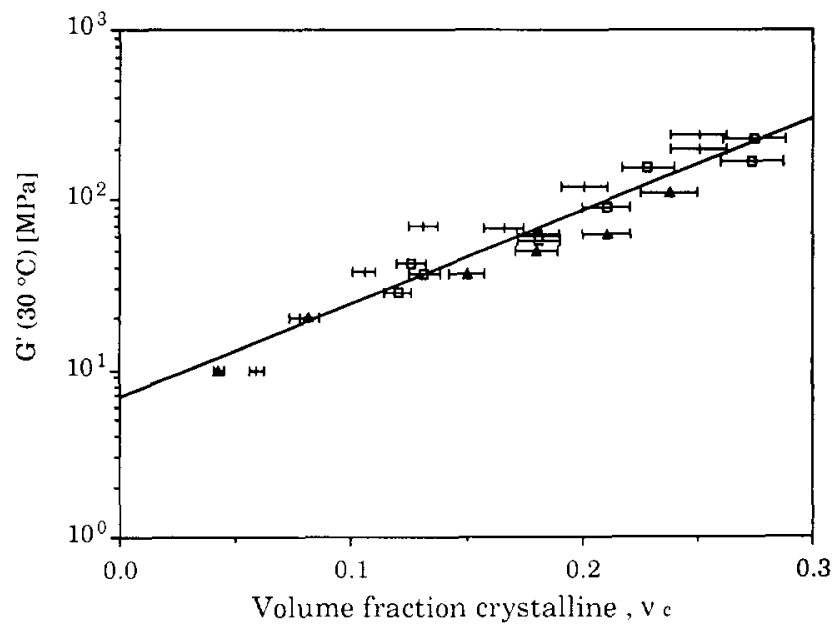

Figure 6 Storage modulus as a function of the volume fraction of crystalline PBT. Copolymers based on PBT and: $(\square)$ dimerized fatty acid; (+) PTMO-glycol $650 / 1000 \mathrm{~g} \mathrm{~mol}^{-1}$ (this work); (A) PTMOglycol $1000 \mathrm{~g} \mathrm{~mol}^{-1}$ (data from ref. 15) 
like the modulus, stress-strain properties, enthalpies, hardness, etc., was also reported by van Berkel et al. ${ }^{20}$. Their work focused on TPEs based on different kinds of polyethers.

Zhu et al. ${ }^{21}$ used an empirical relation between the volume fraction of crystalline material and the modulus:

$$
\log E=v_{\mathrm{c}} \log \frac{E_{\mathrm{c}}}{E_{\mathrm{a}}}+\log E_{\mathrm{a}}
$$

where $E$ represents the modulus, $v_{\mathrm{c}}$ is the volume fraction of crystalline material, $E_{a}$ is the modulus of the amorphous phase and $E_{c}$ the modulus of the purely crystalline material. With the empirical relation (Figure 6) the values for $G_{\mathrm{a}}^{\prime}$ and $G_{\mathrm{c}}^{\prime}$ are calculated to be $6.9 \times 10^{6}$ and $2.2 \times 10^{6} \mathrm{MPa}$. If we assume that $E \sim 3 G^{\prime}$ this will yield $E_{\mathrm{a}}=20.7$ and $E_{\mathrm{c}}=6.6 \times 10^{6} \mathrm{MPa}$. For TPEs based on PTMO, Zhu et al. found $E_{\mathrm{a}}=29.5$ and $E_{\mathrm{c}}=1.95 \times 10^{5} \mathrm{MPa}$. The values for $E_{\mathrm{a}}$ are close to each other. This could be expected, because the data points lie close to the $y$ axis. The calculated $E_{\mathrm{c}}$ values differ considerably and are much higher than can be expected for a randomly ordered $100 \%$ crystalline material. If a more realistic $E_{\mathrm{c}}$ value of $30 \mathrm{GPa}$ is used, no good fit of the data points can be obtained. The empirical relation can fit the data points only with unrealistic values and is too simple for this system. It is probably better to describe the elastic properties of segmented block copolymers as if they were for a reinforced polymer system. The problem one then has is to know the form and size of the reinforcing phase (lamella) and whether there is interconnectivity in the reinforced phase. At low concentrations of reinforcing filler the logarithms of the moduli increase linearly with concentration $^{22}$, as in Figure 6.

\section{CONCLUSIONS}

In this work segmented block copolymers based on dimerized fatty acids and PBT were synthesized. The $T_{\mathrm{g}}$ and $T_{\mathrm{m}}$ could be controlled by variation of the weight fraction of PBT and the molecular mass of the dimerized fatty acid. With WAXS, the average number of carbon atoms directly between the carboxyl groups for $\mathrm{C}_{36}$ dimerized fatty acid is 13 . The branched alkyl side groups contain 21 carbon atoms.

The $T_{\mathrm{g}} \mathrm{s}$ of the TPEs based on the dimerized fatty acids are higher than the $T_{\mathrm{g}}$ of the TPEs based on PTMO. It is shown that $T_{\mathrm{g}}$ can be lowered by utilization of dimerized fatty acid with a higher molecular mass. The higher molecular mass is likely to reduce the compatibility of the PBT segments with the amorphous phase as well as to increase the average length of the PBT segments. These factors will decrease the PBT concentration in the amorphous phase. From the results it seems possible that an extra amorphous phase is formed which contains a higher PBT concentration. The $T_{\mathrm{g}}$ of the soft phase is thus lowered, but broadened by the amorphous phase with high PBT concentration. In the literature, the formation of extra phases with different $T_{g} s$ for polyamide-polyether segmented block copolymers is often described ${ }^{23,24}$. With increased PBT block length the $T_{\mathrm{m}}$ is also increased. The complete rubber plateau is in this way enlarged.
It is also expected that the storage modulus and the melting enthalpy increase with increasing molecular mass of the dimerized fatty acids. The fraction of short, non-crystallizable PBT segments should decrease with increasing molecular mass of the dimerized fatty acids (increasing length of PBT segments). From the results, however, it can be concluded that the storage modulus and the melting enthalpy do not change significantly with molecular mass of the dimerized fatty acid.

A plot of the logarithm of the storage modulus versus the volume fraction of crystalline PBT of the TPEs based on the dimerized fatty acids and PTMO shows a linear relationship. Extrapolating these values to $100 \%$ crystallinity gives unrealistically high values. The segmented block copolymers can best be regarded as 'molecular composites' and the data fitted with composite equations.

\section{ACKNOWLEDGEMENTS}

This work is part of the research programme of the University of Twente and was supported financially by Unichema Chemie, Gouda, The Netherlands. The authors wish to thank A. J. M. Heijnen, E. K. Poels and H. G. Stigter (Unichema, Gouda) for their active interest in the project and E. C. Royens (Unilever Central Laboratory, Vlaardingen) for the WAXS measurements.

\section{REFERENCES}

1 Adams, R. K. and Hoeschele, G. K. in 'Thermoplastic Elastomers' (Eds N. R. Legge, G. Holden and H. E. Schroeder) Hanser, Munich, 1987, Ch. 8

Hoeschele, G. K. Angew. Makromol. Chem. 1977, 58/59, 299

Zeilstra, J. J. Angew. Makromol. Chem. 1985, 137, 83

Hoeschele, G. K. US Pat. 3896078,1975

Brown, M., Hoeschele, G. K. and Witsiepe, W. K. US Pat 3835098,1974

6 Lemaire, J., Arnaud, R. and Gardette, J. Pure Appl. Chem. 1983 55,1603

Hoeschele, G. K. US Pat. 4185003, 1980

Hoeschele, G. K. US Pat. 3856749, 1974

Hoeschele, G. K. US Pat. 3904706, 1975

Hoeschele, G. K. US Pat. 4221703, 1980

Hoeschele, G. K. US Pat. 3954689, i 976

Pripol $1004 \mathrm{C}_{44}$ dimer acid. Product folder Unichema International, Gaida, The Netherlands, 1990

Weiper, A. PhD Thesis University of Münster, 1990

Cella, R. J. J. Polym. Sci. Symp. 1973, 42, 727

Wegner, G. in 'Thermoplastic Elastomers' (Eds N. R. Legge, G Holden and H. E. Schroeder), Hanser, Munich, 1987, Ch. 12

16 Hiemenz, P. C. 'Polymer Chemistry', Marcel Dekker, New York, 1984, p. 217

17 Lilaonitkul, A., West, J. and Cooper, S. L. J. Macromol. Sci. Phys. B 1976, 12, 563

18 Perego, G., Cesari, M. and Vitali, R. J. Appl. Polym. Sci. 1984 29, 1157

19 Wegner, G., Fuji, T., Meyer, W. and Lieser, G. Angew. Makromol. Chem. 1978, 74, 295

20 Van Berkel, R. W. M., De Graaf, S. A. G., Huntjens, F. J. and Vrouenrates, C. M. F. in 'Developments in Block Copolymers-1' (Ed. I. Goodman), Applied Science, London, p. 261

21 Zhu, L. L., Wegner, G. and Bandara, U. Angew. Makromol. Chem. 1981, 182, 3639

22 Kerner, E. H. Proc. Phys. Soc. 1965, 69B, 808

23 Van Hutten, P. F., Walch, E., Veeken, A. H. M. and Gaymans, R. J. Polymer 1990, 31, 524

24 Gaymans, R. J., Schwering, P. and De Haan, J. L. Polymer $1989,30,974$

25 Gaymans, R. J., de Haan, J. L. and van Nieuwenhuize, O. J. Polym. Sci., Polym. Chem. Edn in press 